\title{
SUMBER DAYA MANUSIA KRISTEN DI PAPUA
}

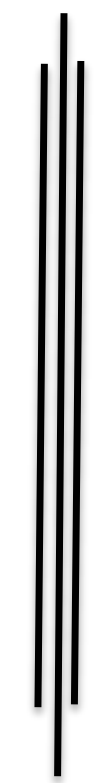

\section{Oleh: \\ Yowenus Wenda \\ 2015070011}

Tugas Makalah ini diserahkan kepada

Dr. Mathias Genafle, M.Pd

Sebagai memenuhi bagian persyaratan untuk mata kuliah Pembangunan Jemaat

\section{Program Doctoral (S-3)}

Program Studi Pendidikan Agama Kristen Sekolah Tinggi Agama Kristen Protestan Negeri (STAKPN) Sentani-Papua 


\section{DAFTAR ISI}

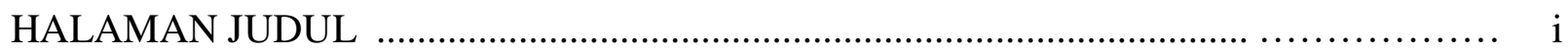

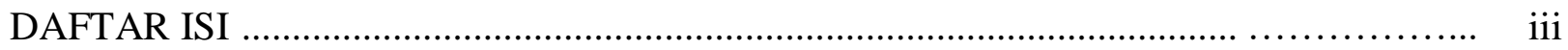

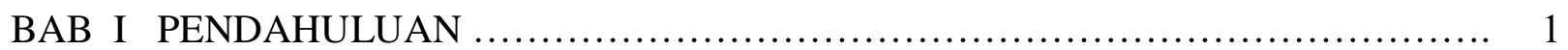

A. Latar Belakang Masalah ................................................................ 1

B. Rumusan Masalah ........................................................................... 1

C. Pembatasan Masalah ........................................................ 1

E. Tujuan Penelitian ............................................................................... 2

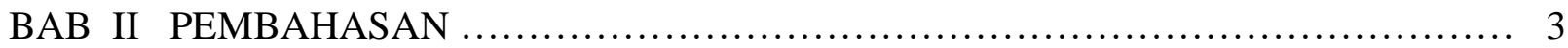

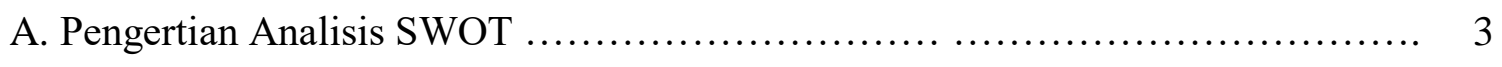

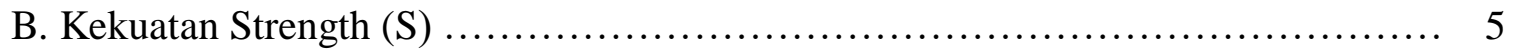

C. Kelemahan Weaknes (W) .............................................. 6

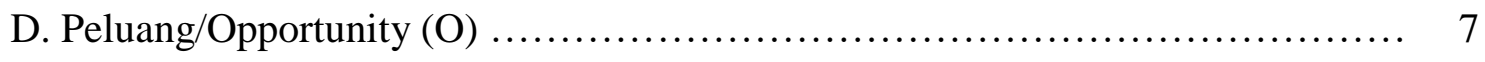

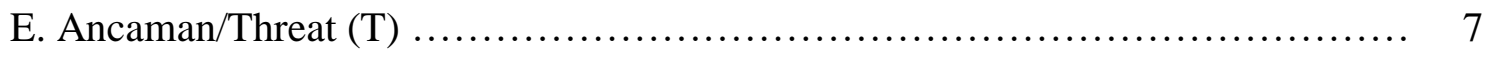

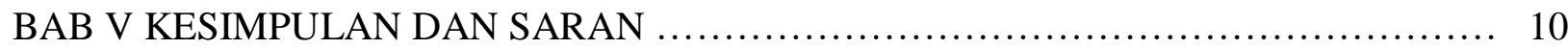

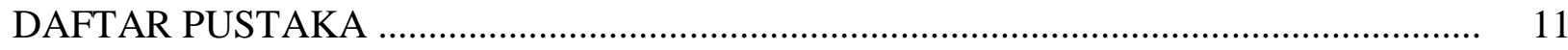




\section{BAB I \\ PENDAHULUAN}

\section{A. Latar Belakang}

Sumber Daya Manusia adalah faktor yang sangat penting dalam suatu organisasi. Apapun bentuk serta tujuannya, organisasi dibuat berdasarkan berbagai visi untuk kepentingan manusia dan dalam pelaksanaan misinya dikelola dan diurus oleh manusia. Manusia merupakan faktor strategis dalam semua kegiatan institusi/organisasi. Maka itu organisasi harus memberikan peluang dan kesempatan sebesar-besarnya pada setiap manusia (generasi muda) untuk meningkatkan potensi dan kemampuan yang dimilkinya baik melalui pendidikan, pelatihan, pembinaan rohani maupun program-program pengembangan lainnya yang berkaitan dengan pengembangan moral dan keimanan. Agar lebih memberikan hasil yang optimal dalam pengelolaan, pengembangan dan pemberdayaan sumber daya manusia harus dilakukan secara terarah dan terencana. Oleh karena itu dalam makalah ini akan menjelaskan kekuatan, kelemahan, keunggulan dan ancaman pengembangan sumberdaya manusia Kristen di berbagai bidan yang ada baik Pendidikan, agama, pemerintah, kesehatan dan ekonomi.

\section{B. Rumusan Maslah}

1. Apakah pengertian analisis SWOT?

2. Bagaimana kondisi sumber daya manusia Kristen di Papua?

3. Bagaimana peran pra pimpinan gereja dan pemerintah dalam mengembangkan sumber daya manusia Kristen di Papua?

\section{Pembatasan Masalah}

1. Pengertian analis SWOT.

2. Analisis SWOT SDM Kristen di Papua.

3. Tanggung jawab para pemimpin gereja dan pemerintah terhadap SDM. 


\section{Tujuan Penulisan Makalah}

1. Mengetahui analisis SWOT sumber daya manusia Kristen di Papua.

2. Mengetahui kondisi sumber daya manusia Kristen di Papua.

3. Mengetahui peran para pimpinan gereja dan pemerintah dalam pengembangan sumber daya manusia Kristen di Papua. 


\section{BAB II \\ PEMBAHASAN}

\section{A. Pengertian Analisis SWOT}

Menurut Freddy Rangkuti (2009: 18) Analisis SWOT adalah identifikasi berbagai faktor secara sistematis untuk merumuskan strategi. Analisis ini didasarkan pada logika yang dapat memaksimalkan kekuatan (Strengths) dan peluang (Opportunities), namun secara bersamaan dapat meminimalkan kelemahan (Weaknesses) dan ancaman (Threats). Proses pengambilan keputusan strategis selalu berkaitan dengan pengembangan misi, tujuan, strategi, dan kebijakan. Dengan demikian perencanaan strategis (strategic planner) harus menganalisis faktor-faktor strategis sumber daya manusia (kekuatan, kelemahan, peluang, dan ancaman) dalam kondisi yang ada saat ini.

Penulisan makalah ini menunjukkan bahwa sumber daya manusia Kristen di Papua dapat ditentukan oleh kombinasi faktor internal dan eksternal. Kedua faktor tersebut harus dipertimbangkan dalam analisis SWOT. SWOT adalah singkatan dari lingkungan Internal Strenghths dan Weaknesses serta lingkungan Eksternal Opportunities dan Threats dalam sumber daya manusia Kristen. Analisis SWOT membandingkan antara faktor eksternal Peluang (opportunities) dan Ancaman (threats) dengan faktor internal Kekuatan (strengths) dan Kelemahan (weaknesses).

Menurut Gitosudarmo (2001: 115) Kata SWOT merupakan pendekatan dari Strenghts, Weakness, Opportunity, and Threats, yang dapat diterjemahkan menjadi : Kekuatan, Kelemahan, Peluang dan Ancaman. Terjemahan tersebut sering disingkat menjadi "KEKEPAN". Dalam metode atau pendekatan ini manusia harus memikirkan tentang kekuatan apa saja yang dimiliki, kelemahan apa saja yang melekat pada diri atau sumber daya manusia Kristen kemudian juga harus melihat kesempatan atau opportunity yang terbuka bagi manusia dan akhirnya manusia harus mampu untuk mengetahui ancaman, gangguan, hambatan serta tantangan (AGHT) yang menghadang di depan. Menurut Wikipedia.org Sumber daya manusia (SDM) adalah salah satu faktor yang sangat penting bahkan tidak dapat dilepaskan dari sebuah organisasi, baik institusi maupun perusahaan. SDM juga merupakan 
kunci yang menentukan perkembangan perusahaan. Pada hakikatnya, SDM berupa manusia yang dipekerjakan di sebuah organisasi sebagai penggerak untuk mencapai tujuan organisasi itu.Sebelum melakukan pola pikir pendekatan analisa SWOT sumber daya manusia Kristen ini di bagi menjadi 3 aspek. Adapun ketiga aspek dalam analisa SWOT ini adalah terdiri dari:

\section{Aspek Global}

Dalam aspek global ini manusia harus mengetahui SWOT yang berkaitan dengan aspek global, aspek yang bersifat garis besar, yang kadang-kadang bersifat internasional serta tidak jarang bernuansa religius. Aspek global ini sangat berkaitan dengan "Misi” dan "Visi” yang harus dikembangkan oleh sumber daya manusia Kristen.

\section{Aspek Strategis}

Aspek strategi ini merupakan penjabaran yang lebih rinci kedalam rencana kerja yang lebih bersifat jangka menengah guna merealisasikan apa yang sudah dirumuskan oleh rencana global di atas. Dalam tahap strategis ini orang Kristen harus mampu memikirkan berbagai alternatif strategi yang mungkin dapat dilakukan untuk merealisasikan rancangan global yakni; pengembangan sumber daya manusia Kristen di Papua, dengan tetap memperhatikan SWOT.

\section{Aspek Operasional}

Aspek operasional merupakan aspek yang bersifat jangka pendek atau tahunan, atau bahkan kurang dari satu tahun. Rencana operasional ini akan menjabarkan secara operasional serta rinci terhadap rencana strategis. Operasionalisasi terhadap strategi yang dipilih dan ditetapkan harus ditindak lanjuti dalam bentuk keterampilan atau keahlian yang harus dikuasai, bentuk-bentuk latihan yang harus dilaksanakan, alat-alat macam apa yang harus disiapkan, begitu pula siapa personalis yang harus melakukan dan sebagainya.

\section{B. Kekuatan Strength (S)}

1. Papua merupakan daerah yang berpenduduk mayoritas Kristen. Hal ini terdapat beberapa denominasi gereja yang melayani di tanah Papua yaitu: Gereja Injili Di Indonesia (GIDI), Gereja Kristen Indonesia (GKI), Gereja Baptis Indonesia, Gereja Kemah Injil, 
Gereja Pantekosta di Indonesia, Gereja Persekutuan Kristen Alkitab Indonesia, Gereja Advent dan ada beberapa denominasi bahkan juga Gareja Katolik. Dengan informasi tersebut hendak menunjukkan bahwa pulau Papua dihuni dan diduduki oleh orang Kristen atau sumber daya manusia Kristen.

2. Para pimpinan gereja di tanah Papua sendang merancang atau membuat berbagai program pelayanan untuk meningkatkan kualitas sumber daya manusia Kristen dalam hal pertumbuhan rohani maupun jasmani.

3. Pemerintah Provinsi Papua maupun daerah berkewajiban memberikan fasilitas kepada lembag-lembaga pendidikan Kristen bahkan Sekolah Tinggi Teologi untuk meningkatkan sumber daya manusia Kristen yang berkualitas di sektor pendidikan.

4. Pemerintah Provinsi Papua maupun masing-masing kabupaten memberikan bantuan dana pendidikan (Beasiswa) kepada setiap pelajar dan mahasiswa yang sedang studi di berbagai kota studi yakni; Papua, luar Papua bahkan di luar Negeri dengan maksud dan tujuan mempersiapkan sumber daya manusia Kristen yang berkualitas dalam berbagai disiplin ilmu baik sektor pemerintahan, pendidikan, ekonomi, kesehatan dan lain sebagainya.

5. Perintah Provinsi Papua bahkan daerah membuat MoU dengan Negara-negara maju dalam berbagai sector untuk meningkatkan sumber daya manusia Kristen di Papua.

\section{Kelemahan/Weaknes (W)}

1. Belum semua sumber daya manusia Kristen di Papua memiliki kompetensi yang sesuai dengan bidang.

2. Para pimpinan gereja di Papua kurang bersatu dalam memikirkan dan mempersiapkan sumber daya manusa Kristen yang bermutu dan berkualitas.

3. Masing-masing denominasi gereja mempertahankan doktrinnya bahkan saling menjatuhkan satu dengan yang lain sehingga sulit untuk menghasilakan sumber daya manusia Kristen berkualitas yang diharapkan oleh gereja. 
4. Sebagian pimpinan gereja hanya memperhatikan atau memenuhi kebutuhan rohaninya sedangkan kebutuhan jasmaninya tidak diperhatikan dengan baik, sehingga menjadi kurang keseimbangan antara kebutuhan rohani dan jasmani.

5. Belum semua pimpinan gereja yang memikirkan tentang regenerasi atau kadernisasi sumber daya manusia Kristen untuk masa yang akan datang.

6. Tidak semua pemerintah daerah yang memberikan bantuan dana pendidikan (Beasiswa) kepada setiap pelajar dan mahasiswa untuk mendukung pendidikan sehingga sulit untuk mempersiapkan sumber daya manusia Kristen yang berkualitas.

7. Permainan politik yang tidak sehat membuat sumber daya manusia sulit untuk berkembang secara kualitas.

8. Kurangnya kerja sama antara para pimpinan gereja dan pemerintah daerah dalam mengatasi tantangan global atau ancaman. Misalnya; penyebaran agama lain di tanah Papua, memberikan izin sebebas-bebasnya untuk mendirikan tempat ibadah atau masjid dan lain sebagainya. Sebenarnya hal ini sangat mematikan sumber daya manusia Kristen di Papua.

\section{Peluang/Opportunity (O)}

1. Masih banyak kesempatan untuk melakukan pengembangan dan peningkatan sumber daya manusia Kristen di Papua yang bermu dan berkualitas.

2. Peluang untuk mengadakan MoU antara para pimpinan gereja dan pemerintah Provinsi Papua dengan Negara-negara maju atau kota-kota maju dalam meningkatkan sumber daya manusia dari berbagai bidang masih terbuka.

3. Kebijakan dan regulasi dibuat oleh pemerintah untuk mengatur kehidupan dan kejahteraan sumber daya manusia Kristen di Papua.

\section{E. Ancaman/Threat (T)}

Para pemeluk agama Islam melakukan berbagai cara dan pendekatan bahkan gerakan segala daya untuk menaklukkan sumber daya manusia Kkristen di Papua. Tujuannya adalah ingin mengokohkan pengakuannya sebagai pemeluk satu agama di Indonesia. Usaha itu tidak 
hanya dilakukan bagi kekristenan di Papua, tetapi juga kepada daerah-daerah kantong Kristen yang lain di Indonesia. Segala sesuatu pendekatan dilakukan termasuk pendekatan kekerasan, yakni mengislamkan kafir atau membunuh kafir, sebab itu merupakan "ajaran agama yang sempurna yang diajarakan oleh nabi yang sempurna" itu ${ }^{1}$.

Dalam hal ini orang Muslim telah memasuki dan telah menduduki di berbagai macam lini. Pendirian tempat ibadah atau musolah sedang menjamur hampir di seluruh pelosok Papua, pada hal tidak sesuai dengan aturan pendirian tempat ibadah sebagaimana di ataur dalam Peraturan Bersama Menteri Agama dan Menteri Dalam Negeri No. 9 tahun 2006 itu. Selain itu, telah berbagai kelompok daqwah di seluruh Papua seperti Forum Komunikasi Muslim di Pegunungan Tengah yang dipusatkan di Wamena dengan tujuan untuk membina umat muslim di Wamena. Selain itu memiliki tujuan untuk menyentu tiga kebutuhan utama manusia di seluruh wilayah pengungan Tengah, yakni: bidang kesehatan, bidang pendidikan dan bidang ekonomi. Kemudian FKMPT telah membuka sebuah pesantren dengan pola Sekolah Dasar di Wamena, yang siswanya $80 \%$ orang Papua yang difasilitasi oleh Asisten III Gubenur Bapak Drs. H.Ibrahim Is Badaruddin, MM. Oleh karena misi dan kegiatann organisasi sangat jelas sehingga organisasi tersebut telah didaftar di KESBANGPOL serta Kementerian Agama Wilayah Papua sebagai lembaga berbadan hukum yang sah. Selain itu, banyak sumber daya manusia Kristen di Papua yang berpindah tempat ibadah, yakni dari gereja ke masjid. Karena lemahnya pengajaran firman Allah oleh gereja kepada umatnya dan lemahnya pemerintah daerah dalam mempersiapkan sumber daya manusia yang berkualitas sehingga sulit menangani masalah kesehatan, kemiskinan dan pendidikan sehingga tidak sedikit orang pindah tempat ibadah dan dijangkau oleh orang Islam. Ada beberapa sumber daya manusia Kristen yang berhasil dipindahkan merupakan sosok figur yang dapat mempengaruhi orang lain yaitu:

1. Kepala Suku Lembah Baliem yakni Obahorok Kosay berganti nama menjadi Abdul Rahman. Setelah menjadi muslim, dia menikah dengan seorang guru agama Islam, seorang gadis asli Jakarta. Akhirnya perkawinan silang ini membuka peluang besar

\footnotetext{
${ }^{1}$ Shorrosh, Anis A. Kebenaran Di Ungkapan: Pandangan Seorang Arab Kristen Tentang Islam. (Jakarta: Kelompok Kerja PHILIA, 1994), 36.
} 
untuk terjadinya pengajaran agama Islam di Lembah Baliem semakin melebar, bahkan yang sudah mulai banyak memeluk agama Islam.

2. Saul Yenu, saat menginjak usia 68 tahun, Kepala Suku Besar Serui memutuskan menjadi seorang Muslim. Setelah belajar menjadi Muslim dia naik haji, uangnya hasil bantuan Amien Rais, mantan Ketua MPR-RI. Menurut pengakuan Yenu, bahwa paling tidak hingga kini sudah mengislamkan 50 orang Papua, sehingga dengan bangganya ia berkata: Alhamdulillah! Sebanyak 20 orang di antaranya sudah naik haji. Keluarga pun beberapa mengikuti jejak saya. Anak saya, istri saya, dua di antaranya pun sudah jadi mualaf. Saya akan terus berusaha agar seluruh penduduk Papua terbebas dari keterbelakangannya dengan cara mengajak mereka masuk Islam,” ujar suami empat istri dan 37 anak ini.

4. Salah satu Kabupaten Pegunungan Tengah Papua, yakni Yahukimo muncul Seorang Tokoh Da'i asal Nasional Al-Ustadz Saiful Islam Al-Payage. Dan menurut kaum muslim bahwa munculnya tokoh muslim ini merupakan ikon simbolik bangkitnya muslim pribumi di wilayah Pegunungan Tengah Papua yang selama ini dicap sebagai muslim yang terbelakang. Kemudian denganterbentuknya Forum Komunikasi Muslim Pegunungan Tengah secara politis memperlihatkan eksistensi Muslim Pribumi dipublic sehingga orang lain mau tidak mau, harus mengakui keberadaan komunitas muslim Pegunungan Tengah Papua. Berangsur-angsur Forum Komunikasi Muslim Pegunungan Tengah menata diri atau berkembang dan Insya Allah akan menjadi Pesat keseluruh Alam di Papua. Dan hal itu sebagaimana dalil Al-Qur'an Surah Al-Anbiyya ayat 107 yang artinya:" Tidak-lah Kami Mengutus Engkau Wahai Muhammad, Melainkan Menjadi Rahmat Untuk Seluruh Alam.” Ini menjadi dasar dalam semua pergerakan, yaitu untuk menjadi berkat bagi seluruh isi alam terutama bagi manusia yang berbeda pandangan dengan Islam.

5. Kurangnya pendidikan atau pemahaman dan tidak adanya pengalaman berpolitik, sehingga ketika UU OTSUS digulirkan yang menyebabkan perluasan wilayah kekuasaan dengan hadirnya banyak partai politik, maka bermunculan gesekan dan konflik antar suku, antar daerah, antar kelompok atau antar partai, bahkan antar agama dan antara orang asli Papua. 


\section{BAB II \\ PENUTUP}

Kesimpulan: Analisis SWOT merupakan Strenghths, Weaknesses, Opportunities dan Threats dalam sumber daya manusia Kristen. Pengembangan Sumber Daya Manusia Kristen adalah aktifitas yang sangat penting dalam suatu organisasi, menjaga agar organisasi tetap tumbuh, khususnya pada para pimpinan gereja dan pemerintah dalam meningkatkan kualitas sumber daya manusia Kristen di Papua.

Saran: Diharapkan kepada para pimpinan gereja dan pemerintah untuk selalu bekerja keras dalam meningkatkan SWOT sumber daya manusia Kristen di Papua dengan memanfaatkan peluang peluang yang ada agar dapat meningkatkan kualitas sumber daya manusia. 


\section{Dafatar Pustaka}

Shorrosh, Anis A. Kebenaran Di Ungkapan: Pandangan Seorang Arab Kristen Tentang Islam (Jakarta: Kelompok Kerja PHILIA, 1994), 36.

http://www.google.co.id/?gws_rd=cr\&ei=Msb8VeqEFYuLuwT5zYeoCQ\#q=pengertian+analisis +swot+menurut+para+ahli, diakses pada 5 September 2015

http://www.google.co.id/Pengertian+SWOT, diakses pada 5 September 2015

https://id.wikipedia.org/wiki/Sumber_daya_manusia, diakses pada 5 September 2015 